Vol.1 No.1 Januari 2018

ISSN 2614-2775

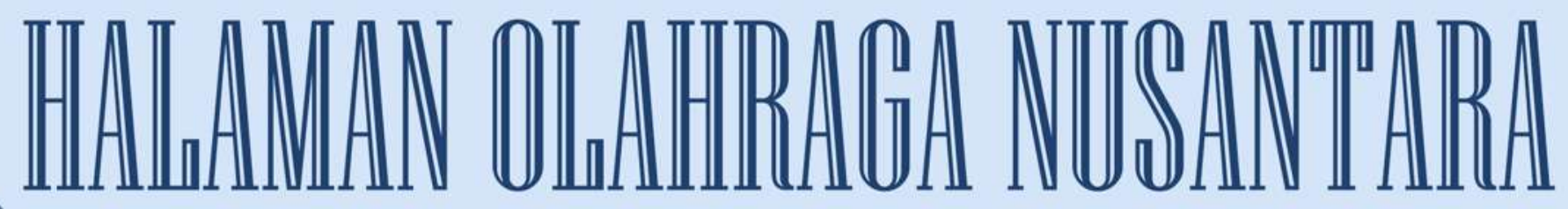

Curnal \&lmu Q Xeolahragaan

Diterbitkan Oleh:

Program Studi Pendidikan Olahraga

Pakultas Keguruan dan Ilmu Pendidikan

Universitas PGRI Palembang

\begin{tabular}{|c|c|c|c|c|c|}
\hline Jurnal & Volume & Nomor & Halaman & Palembang & ISSN \\
\hline IItaman Oahraya Vissantara & 1 & 1 & $1 \cdot 132$ & 2018 & 2014.27175 \\
\hline
\end{tabular}


Artikel Ilmiah

Perbedaan Variasi Latihan Juggling dan Rasio Koordinasi Mata-Kaki terhadap Hasil Kontrol Bola dari Tendangan Jarak Jauh Sepak Bola Hengki Kumbara

Hubungan Antara Kekuatan Otot Tungkai dan Kekuatan Otot Lengan terhadap Hasil Kecepatan Renang 50 Meter Gaya Bebas pada Atlet Putri Club Bangka Swimming

Farizal Imansyah

Motivasi Mahasiswa PGSD dalam Olahraga Rekreasi di Water Fun Kota Palembang

M. TaheriAkikbar

Pengaruh Metode Sirkuit terhadap Kemampuan Teknik Dasar Sepakbola pada Kegiatan Ekstrakurikuler Siswa SMAN 5 Kabupaten Tebo Alek Oktadinata

Kontribusi. Daya Ledak Otot Thung:kai dan Kelentukan dengan [1asil] Lompat Tinggi Gaya Flop Mahasiswa Program Studi Pendidikan Olahraga Universitas PG:RIPalembang IIham Arvan Junaidi

Kemampuan Meng.gining Bola (IStudi Korelasional Kecepatan ( $\left.x_{1}\right)$ dan Kelineahan $\left(x_{2}\right)$ dengan Kemampuan Dribel pada Permainan Sepabola Siswa Sekolah Menengah Pertama) Putwi Cicilla Kristina

Revitalisasi Masyarakat ¿iban/Perkotaan Melalui Olahraga Petanque Arcdo okilanda

Peranan Mata Pelajaran Pendidikan Jasmani dalam Meningkatkan Kesadaran Kesehatan \$iswa đi Lingkungan \$ekolah Dasar

Negeri nur Tegalkalong Kabupaten sumedang

№ Siti nurfaeni Sofa dan Anggi Setia Lengkana

Peran Motor Educability di dalam Meningkatan Keterampilan Olahraga pada Pembelajaran Penjas

gieru Syarili Lesmana

MơtivasiAnggota Pusat Kebugaran dalam Mengikuti Latihan Fitness padaKota Sekaycu Sugar Wanto

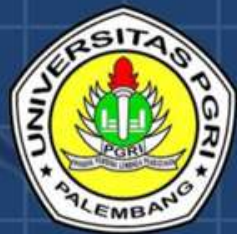

Program Studi Pendidikan Olahraga Fakultas Keguruan dan Ilmu Pendidikan Universitas PGRI Palembang 
ISSN 2614-2775

\section{HALAMAN OLAHRAGA NUSANTARA}

Jurnal Ilmu Keolahragaan

Volume 1, Nomor 1, Januari 2018

Pelindung/Penasehat

Dr. H. Bukman Lian, M. M., M. Si.

Penanggung Jawab

Dr. Dessy Wardiah, M. Pd.

Ketua Dewan Redaksi

Drs. M. Nirwan, M. Pd.

\section{Wakil Ketua Dewan Redaksi}

Ilham Arvan Junaidi, M. Pd.

\section{Sekretaris}

Nasrullah, M. Pd.

Penyunting Pelaksana

Rafel Orlando, M. Pd

Ardo Okilanda, M. Pd

\section{Penyunting Ahli/ Mitra Bestari}

Prof. Dr. A. Sofyan Hanif, M. Pd (Universitas Negeri Jakarta)

Dr. Ronni Yenes, M. Pd (Universitas Negeri Padang)

Dr. Putri Cicilia Kristina, M. Pd (Universitas PGRI Palembang)

\section{Tata Usaha}

M. Taheri Akbar, M. Pd

\section{Setting:}

Dede Dwiansyah Putra, M. Pd

Alamat Redaksi:

Prodi Pendidkan Olahraga Fakultas Keguruan Ilmu dan Pendidikan Universitas PGRI Palembang

Jl. Jendral A. Yani Lorong Gotong Royong 9/10 Ulu Palembang Telp. 0711-510043, Fax. 0711-514782

e-mail jurnal: rafelorlando333@gmail.com

e-mail : ardo.oku@ univpgri-palembang.ac.id

website: univpgri-palembang.ac.id 


\section{DAFTAR ISI}

Perbedaan Variasi Latihan Juggling dan Rasio Koordinasi Mata-Kaki terhadap Hasil Kontrol Bola dari Tendangan Jarak Jauh Sepak Bola

Hubungan Antara Kekuatan Otot Tungkai dan Kekuatan Otot Lengan terhadap Hasil Kecepatan Renang 50 Meter Gaya Bebas pada Atlet Putri Club Bangka Swimming

- Farizal Imansyah

Motivasi Mahasiswa PGSD dalam Olahraga Rekreasi di Water Fun Kota Palembang

- $\quad$ M. Taheri Akhbar

Pengaruh Metode Sirkuit terhadap Kemampuan Teknik Dasar Sepakbola pada Kegiatan Ekstrakurikuler Siswa SMAN 5 Kabupaten Tebo

- Alek Oktadinata

Kontribusi Daya Ledak Otot Tungkai dan Kelentukan dengan Hasil Lompat Tinggi Gaya Flop Mahasiswa Program Studi Pendidikan Olahraga Universitas PGRI Palembang

- Ilham Arvan Junaidi

Kemampuan Menggiring Bola (Studi Korelasional Kecepatan $\left(\mathrm{x}_{1}\right)$ dan Kelincahan $\left(\mathrm{x}_{2}\right)$ dengan Kemampuan Dribel pada Permainan Sepabola Siswa Sekolah Menengah Pertama)

- Putri Cicilia Kristina

Revitalisasi Masyarakat Urban/Perkotaan Melalui Olahraga Petanque

- $\quad$ Ardo okilanda

Peranan Mata Pelajaran Pendidikan Jasmani dalam Meningkatkan

Kesadaran Kesehatan Siswa di Lingkungan Sekolah Dasar

Negeri III Tegalkalong Kabupaten Sumedang

- $\quad$ N. Siti nur'aeni Sofa dan Anggi Setia Lengkana

Peran Motor Educability di dalam Meningkatan Keterampilan

Olahraga pada Pembelajaran Penjas

- Heru Syarli Lesmana 
Motivasi Anggota Pusat Kebugaran dalam Mengikuti Latihan Fitness pada Kota Sekayu

Sugar Wanto 


\title{
PERANAN MATA PELAJARAN PENDIDIKAN JASMANI DALAM MENINGKATKAN KESADARAN KESEHATAN SISWA DI LINGKUNGAN SEKOLAH DASAR NEGERI III TEGALKALONG KAB. SUMEDANG
}

\author{
Oleh: N. Siti Nur'aeni Sofa dan Anggi Setia Lengkana \\ (Dosen STKIP Sebelas April Sumedang)
}

\begin{abstract}
Abstrak
Dalam meningkatkan kesadaran kesehatan siswa perlu adanya kesadaran dan kepedulian dari siswa terhadap situasi dan kondisi kesehatan dalam dirinya dan lingkungannya, oleh karena itu peran dari mata pelajaran pendidikan jasmani dalam membudayakan kesehatan siswa di sekolah sangatlah penting dalam memberikan pendidikan kesehatan dan bimbingan serta mengupayakan pengembangan pada siswa dalam membiasakan diri hidup sehat dalam kehidupan sehari-harinya. Karena dengan membiasakan siswa dengan hidup sehat akan berpengaruh pada perkembangan dan pertumbuhan siswa. Perkembangan dan pertumbuhan siswa yang cenderung tidak terlihat adalah pertumbuhan otak yang mendukung pada perkembangan cara berpikir dan kecerdasan.Berdasarkan pada masalah-masalah yang telah diuraikan tersebut, maka tujuan yang hendak dicapai dalam penelitian ini adalah "Ingin mengetahui sejauhmana peranan mata pelajaran pendidikan jasmani dalam meningkatkan kesadaran kesehatan siswa dilingkungan Sekolah Dasar Negeri III Tegalkalong”. Untuk menjawab rumusan masalah dan hipotesis yang diajukan, maka penelitian yang digunakan penulis adalah metode deskriptif. Dalam penelitian ini penulis memilih instrument pengumpulan data dengan cara menyebarkan angket (kuesioner) sebagai instrument dalam pengumpulan data. Berdasarkan hasil pengolahan dan analisis data mengenai peranan mata pelajaran pendidikan jasmani dalam meningkatkan kesadaran kesehatan siswa, yang dilakukan di Sekolah Dasar Negeri Tegalkalong III, dapat ditarik kesimpulan bahwa,"Pelajaran pendidikan jasmani memiliki peranan yang sangat besar dalam meningkatkan kesadaran kesehatan siswa di lingkungan Sekolah Dasar Negeri Tegalkalong III. Besarnya peranan mata pelajaran pendidikan jasmani dalam meningkatkan kesadaran kesehatan siswa yaitu sebesar $55.96 \%$.
\end{abstract}

Kata Kunci: Pendidikan Jasmani, Kesadaran Kesehatan, Lingkungan Sekolah Dasar 


\title{
THE ROLE OF PHYSICAL EDUCATION LEARNING IN IMPROVING STUDENT HEALTHY LIFE AWARENESS AT THE BASIC SCHOOL III TEGALKALONG KAB. SUMEDANG
}

\begin{abstract}
In raising the awareness of health students need the awareness and awareness of students on the situation and health conditions in themselves and the environment, therefore the role of physical education subjects in nurturing the health of students in schools is very important in providing health education and guidance and seek development in students in getting used to healthy living in everyday life. Because by familiarizing students with a healthy life will affect the development and growth of students. The development and growth of students who tend not to be seen is the growth of the brain that supports the development of ways of thinking and intelligence. Based on the problems that have been described, the goal to be achieved in this study is "Want to know how far the role of physical education subjects in improving awareness of student health in elementary school of State III Tegalkalong ". To answer the formulation of the problem and the hypothesis proposed, the research used by the author is descriptive method. In this study the authors chose the data collection instrument by spreading the questionnaire (questionnaire) as an instrument in data collection. Based on the results of processing and data analysis on the role of physical education subjects in improving students' health awareness, conducted in Tegalkalong III State Elementary School, it can be concluded that, "Physical education lessons have a very big role in improving health awareness of students in elementary school Negeri Tegalkalong III. The magnitude of the role of physical education subjects in raising students' health awareness is $55.96 \%$.
\end{abstract}

Keywords: Physical Education, Health Awareness, Elementary School Environment

\section{A. PEndahuluan}

Menurut Partakusumah (1997: 17), "Pendidikan jasmani pada dasarnya merupakan pendidikan melalui aktivitas jasmani yang dijadikan sebagai media untuk mencapai perkembangan individu secara menyeluruh." Namun perolehan keterampilan dan perkembangan lain yang berisi jasmani itu juga sekaligus sebagai tujuan. Melalui pendidikan jasmani, siswa disosialisasikan kedalam aktivitas jasmani termasuk keterampilan berolahraga. Oleh karena itu, tidaklah mengherankan apabila banyak yang meyakini dan mengatakan bahwa pendidikan jasmani merupakan bagian dari pendidikan menyeluruh dan sekaligus memiliki 
potensi yang strategis untuk mendidik.

Di dalam intensifikasi penyelengaraan pendidikan sebagai suatu proses pembinaan manusia yang berlangsung seumur hidup, peranan pendidikan jasmani adalah sangat penting, yang memberikan kesempatan kepada siswa untuk terlibat langsung dalam aneka pengalaman belajar melalui aktivitas jasmani, bermain dan olahraga yang dilakukan secara sistematis. Pembekalan pengalaman belajar itu diarahkan untuk membina, sekaligus membentuk gaya hidup sehat dan aktif sepanjang hayat.

Dengan pendidikan jasmani siswa akan memperoleh berbagai ungkapan yang erat kaitannya dengan kesan pribadi yang menyenangkan serta berbagai ungkapan yang kreatif, inovatif, terampil, memiliki kebugaran jasmani, kebiasaan hidup sehat dan memiliki pengetahuan serta pemahaman terhadap gerak manusia. Dalam proses pembelajaran pendidikan jasmani guru diharapkan mengajarkan pembiasaan pola hidup sehat. Salah satu yang menjadi tujuan pendidikan jasmani yaitu mengembangkan keterampilan pengelolaan diri dalam upaya pengembangan dan pemeliharaan kebugaran jasmani serta pola hidup sehat melalui berbagai aktivitas jasmani dan olahraga. Pendidikan jasmani juga dapat membentuk gaya hidup yang sehat. Dengan kesadarannya anak akan mampu menentukan sikap bahwa kegiatan fisik merupakan kebutuhan pokok dalam hidupnya, dan akan tetap dilakukan di sepanjang hayat. Sikap itulah yang kemudian akan membawa anak pada kualitas hidup yang sehat, sejahtera lahir dan batin.

Melalui olahraga yang teratur, terprogram dan terencana dengan baik maka akan mampu memelihara bahkan meningkatkan derajat kesehatan yang akan tampak pada tingkat kesegaran jasmaninya. Melakukan olahraga berarti menanamkan modal bagi tubuh, kesehatan yang lebih baik, hidup yang lebih bergairah, kebahagiaan dan kesinambungan. Pendidikan kesehatan adalah usaha yang diberikan berupa bimbingan kepada seseorang atau anak didik tentang kesehatan yang meliputi seluruh aspek pribadi (fisik, mental dan sosial), agar 
dapat tumbuh dan berkembang secara harmonis. Pada saat ini pendidikan kesehatan di sekolah dijadikan satu dengan pendidikan jasmani atau pendidikan olahraga. Selain meningkatkan pengetahuan tentang kesehatan kepada anak juga diharapkan pendidikan kesehatan digunakan sebagai tempat mendidik anak untuk ber pola hidup sehat.

Anak yang belum paham tentang arti pola hidup sehat akan diberikan pengertian, pemahaman, dan pelatihan tentang hidup sehat. Dengan demikian siswa akan menanamkan dalam dirinya tentang kesehatan fisik, mental dan sosialnya. Kesehatan adalah keadaan sejahtera dari badan, jiwa, dan sosial yang memungkinkan setiap orang hidup produktif secara sosial dan ekonomis. Pendidikan kesehatan adalah proses membantu seseorang, dengan bertindak secara sendiri-sendiri ataupun secara kolektif, untuk membuat keputusan berdasarkan pengetahuan mengenai hal-hal yang memengaruhi kesehatan pribadinya dan orang lain. Sedangkan hidup sehat adalah suatu hal yang sangat didambakan oleh setiap orang. Penerapan hidup sehat harus terlebih dahulu didasari pemahaman hidup sehat itu sendiri. Hidup sehat adalah segala upaya yang dilakukan untuk dalam kondisi sehat dan menjaga kondisi tersebut terus meningkat.

Sedangkan menurut Giriwijoyo (2007: 8), "Sehat adalah sejahtera jasmani, rohani dan sosial; bukan hanya bebas dari penyakit, cacat ataupun kelemahan". Jadi pengertian sehat disini sangat luas. Sehat jasmani, sehat rohani dan sehat sosial adalah penertian sehat yang menyeluruh yang harus diraih dan dijaga oleh setiap orang.

Dalam meningkatkan kesadaran kesehatan siswa perlu adanya kesadaran dan kepedulian dari siswa terhadap situasi dan kondisi kesehatan dalam dirinya dan lingkungannya, oleh karena itu peran dari mata pelajaran pendidikan jasmani dalam membudayakan kesehatan siswa di sekolah sangatlah penting dalam memberikan pendidikan kesehatan dan bimbingan serta mengupayakan pengembangan pada siswa dalam membiasakan diri hidup sehat dalam kehidupan 
sehari-harinya. Karena dengan membiasakan siswa dengan hidup sehat akan berpengaruh pada perkembangan dan pertumbuhan siswa. Perkembangan dan pertumbuhan siswa yang cenderung tidak terlihat adalah pertumbuhan otak yang mendukung pada perkembangan cara berpikir dan kecerdasan.

\section{B. METODOLOGI PENELITIAN}

\section{Landasan Ilmiah Pendidikan Jasmani}

Pandangan pendidikan modern menganggap bahwa manusia merupakan satu kesatuan yang utuh (holistik) yang mengandung arti bahwa jiwa dan raga merupakan bagian integral yang tidak dapat dipisahkan satu sama lain. Sejalan dengan konsep tersebut maka pendidikan jasmani diartikan sebagai proses pendidikan melalui aktivitas jasmani dan sekaligus merupakan proses pendidikan untuk meningkatkan kemampuan jasmani. Sutrisno (2001: 54) menjelaskan bahwa:

"Pendidikan jasmani pada dasarnya merupakan bagian integral dari sistem pendidikan secara keseluruhan, bertujuan untuk mengembangkan aspek kesehatan, kebugaran jasmani, keterampilan berfikir kritis, stabilitas emosional, keterampilan sosial, penalaran dan tindakan moral melalui aktivitas jasmani dan olahraga."

Di dalam intensifikasi penyelengaraan pendidikan sebagai suatu proses pembinaan manusia yang berlangsung seumur hidup, peranan Pendidikan Jasmani adalah sangat penting, yang memberikan kesempatan kepada siswa untuk terlibat langsung dalam aneka pengalaman belajar melalui aktivitas jasmani, bermain dan olahraga yang dilakukan secara sistematis. Pembekalan pengalaman belajar itu diarahkan untuk membina, sekaligus membentuk gaya hidup sehat dan aktif sepanjang hayat.

Sedangkan menurut Taryana (2001: 55), "Pendidikan jasmani merupakan media untuk mendorong perkembangan keterampilan motorik, kemampuan fisik, pengetahuan, penalaran, penghayatan nilai (sikap-mental- 
emosional-spiritual-sosial), dan pembiasaan pola hidup sehat yang bermuara untuk merangsang pertumbuhan serta perkembangan yang seimbang”.

Dengan pendidikan jasmani siswa akan memperoleh berbagai ungkapan yang erat kaitannya dengan kesan pribadi yang menyenangkan serta berbagai ungkapan yang kreatif, inovatif, terampil, memiliki kebugaran jasmani, kebiasaan hidup sehat, dan memiliki pengetahuan serta pemahaman terhadap gerak manusia. Dalam proses pembelajaran Pendidikan Jasmani guru diharapkan mengajarkan berbagai keterampilan gerak dasar, teknik dan strategi permainan dan olahraga, internalisasi nilai-nilai (sportifitas, jujur, kerjasama, dan lain-lain) serta pembiasaan pola hidup sehat. Pelaksanaannya bukan melalui pengajaran konvensional di dalam kelas yang bersifat kajian teoritis, namun melibatkan unsur fisik, mental, intelektual, emosi dan sosial. Aktivitas yang diberikan dalam pengajaran harus mendapatkan sentuhan didaktik-metodik, sehingga aktivitas yang dilakukan dapat mencapai tujuan pengajaran.

Tidak ada pendidikan yang tidak mempunyai sasaran paedagogis, dan tidak ada pendidikan yang lengkap tanpa adanya pendidikan jasmani, karena gerak sebagai aktivitas jasmani adalah dasar bagi manusia untuk mengenal dunia dan dirinya sendiri yang secara alamiah berkembang searah dengan perkembangan zaman.

Menurut Kusnandar (2000: 76), "Pendidikan jasmani pada hakekatnya adalah proses pendidikan yang memanfaatkan aktivitas fisik untuk menghasilkan perubahan holistik dalam kualitas individu, baik dalam hal fisik, mental, serta emosional". Pendidikan jasmani memberlakukan anak sebagai sebuah kesatuan utuh, makhluk total dari pada hanya menganggapnya sebagai seseorang yang terpisah kualitas fisik dan mentalnya.

Menurut Zaenal (2008: 65), aktivitas jasmani dapat kita telusuri dari beberapa sudut pandang yang antara lain meliputi hal berikut.

a. Aktivitas jasmani sebagai perilaku gerak manusia yang berada dibawah 
payung konsep gerak (movement science).

b. Aktivitas jasmani sebagai olahraga yang ditujukan berdasarkan disiplin olahraga (sport discipline).

Selain aktivitas jasmani itu sendiri, para penyelenggara pendidikan jasmani dituntut harus memahami secara mendalam beberapa disiplin lainnya yang berada dibawah payung pendidikan jasmani. Beberapa diantaranya adalah: Sport Medicine, Training Theory, Sport Biomekanik, Sport Psikologi, Sport Pedagogi, Sport Sosiologi, Sport History, dan Sport Philisopy.

Menurut Sadoso (1989: 9),

"Kesegaran jasmani adalah kemampuan seseorang untuk melakukan tugas sehari-hari dengan gampang, tanpa merasa lelah yang berlebihan dan mempunyai sisa atau cadangan tenaga untuk menikmati waktu senggangnya. Dapat pula ditambahkan dengan baik walaupun dalam keadaan sukar."

Berdasarkan kutipan di atas, maka kesegaran jasmani merupakan faktor yang penting dan mutlak harus dimiliki oleh setiap manusia demi kelangsungan hidup serta meningkatkan produktivitas kerjanya. Sedangkan seseorang tanpa memiliki kesegaran jasmani yang baik atau tidak sesuai dengan kebutuhan tuntutan kerja, maka orang tersebut tidak bisa meningkatkan produktivitas kerja. Oleh karena itu, jika tingkat kesegaran jasmani tinggi, maka tingkat produktivitasnyapun tinggi.

Seseorang yang berada dalam keadaan segar, ia cukup mempunyai kekuatan, kemampuan, kesanggupan, daya kreasi dan daya tahan untuk melakukan pekerjaan dengan efisien tanpa menimbulkan kelelahan yang berarti. Yang dimaksud dengan tidak menimbulkan kelelahan yang berarti adalah selesai bekerja, masih mempunyai cukup energi dan semangat untuk melakukan kegiatan-kegiatan lainnya.

Kesegaran jasmani merupakan cikal bakal dari kesegaran secara umum, seperti dikemukakan oleh Ichsan (1989: 55) sebagai berikut.

"Kesegaran jasmani ini merupakan ciri utama cikal bakal dari 
kesegaran secara umum, jadi apabila seseorang dalam keadaan segar salah satu aspek pokok yang nampak adalah keadaan penampilan jasmaninya. Dengan demikian seseorang tidak dapat mencapai kesegaran secara menyeluruh atau umum tanpa disadari oleh keadaan kesegaran jasmani yang baik."

Dengan memahami pengertian kesegaran jasmani dari pendapatpendapat di atas, jelas bahwa kesegaran jasmani itu didukung oleh banyak unsur yang satu sama lain saling berhubungan.

\section{Komponen-komponen Kesegaran Jasmani}

Komponen kesegaran jasmani mempunyai kriteria yang ditentukan oleh dua komponen, yaitu komponen kesehatan dan komponen keterampilan. Seperti yang dikemukakan oleh Hopen dalam Ichsan (1989: 55) sebagai berikut.

"Kriteria kesegaran jasmani ditentukan oleh dua komponen yaitu komponen kesehatan dan komponen keterampilan yang bersifat atletis. Komponen kesehatan terhadap kesegaran jasmani terdiri dari empat hal pokok yaitu : a.) cardiovascular endurance (daya tahan kardiovaskular), b.) muscular endurance dan strength (daya tahan otot dan kekuatan otot), c.) body composition (keseimbangan pertumbuhan tubuh), d.) flexibility (kelentukan). Sedangkan komponen keterampilan terdiri dari lima hal pokok yaitu : a.) muscular power (kekuatan otot ), b.) agility (kelincahan), c.) speed (kecepatan), d.) muscle bulk (ketebalan otot), e.) posture (bentuk tubuh)."

\section{Komponen-komponen Kesehatan}

Kesehatan merupakan harta yang paling berharga di dunia ungkapan tersebut, terucap ketika orang sudah tidak sehat lagi atau dengan perkataan lain bila orang tersebut sudah jatuh sakit. Pendidikan kesehatan merupakan sebuah proses yang amat kompleks. Oleh karena itu, setiap orang perlu

diberikan informasi tentang kesehatan agar dapat menjalankan hidup yang sesuai dengan prinsip kesehatan. Kesehatan bertujuan untuk peningkatan 
derajat kesehatan masyarakat secara optimal. Guna pencapaian tujuan tersebut, masyarakat didorong agar tahu permasalahan dan pencarian jalan untuk mengatasi berbagai masalah yang muncul. Dalam upaya membina gaya hidup sehat itu, terdapat sejumlah faktor yang ikut terlibat. Guru pendidikan jasmani dan kesehatan menduduki posisi yang sangat strategis dalam meletakkan dasar yang kuat bagi kualitas hidup sehat generasi di masa yang akan datang.

Terkait dengan tugas ini adalah pengembangan pengalaman belajar di sekolah. Faktor lingkungan masyarakat sekitar juga ikut mempengaruhi upaya untuk mempromosikan kesehatan anak-anak, karena itu pula evaluasi hasil belajar peserta didik perlu memperhitungkan aspek ekonomi, pendidikan, hukum dan lingkungan sekitar yang mempengaruhi kualitas program pendidikan kesehatan. Perilaku hidup sehat harus ditanamkan sedini mungkin dimulai dari pendidikan dasar baik di rumah lebih-lebih di sekolah. Sebab perilaku hidup sehat merupakan kebiasaan yang butuh ketelatenan dalam penanaman hidup sehat pada setiap anak. Penanaman hidup sehat harus diawali dari individu anak untuk dapat dimengerti pengetahuan tentang kesehatan pribadi masing-masing.

Kesehatan merupakan dasar untuk peningkatan dan pembinaan kesegaran jasmani. Salah satu bentuk modal pembangunan adalah sumber daya manusia yang sehat, yaitu sehat fisik, mental dan sosial. Agar manusia Indonesia berproduktifitas yang optimal diperlukan derajat kesehatan yang tinggi. Supaya hidup sehat kita harus membiasakan makanan yang cukup dan baik mutunya, menjaga kesehatan diri (badan dan pakaian) memerlukan kebersihan rumah serta lingkungannya. Menurut Sjarifuddin (1991), "Kebiasaan hidup bersih harus diajarkan sedini mungkin di rumah tangga dan kemudian diteruskan di sekolah sehingga berangsur-angsur menjadi bahagia dari perilaku kehidupan bersih, maka upaya pembinaan dan peningkatan kesehatan anak - anak dan masyarakat akan menjadi lebih mudah". Di sekolah 
siswa kurang mendapat pelajaran yang memadai tentang kesehatan pribadi. Hal ini dapat dilihat setiap memasuki jam mata pelajaran olahraga atau pendidikan jasmani maka guru pendidikan jasmani akan selalu menyuruh siswa untuk melakukan aktifitas cabang-cabang olahraga seperti: atletik, sepak bola, voli, senam, dan lain sebagainya. Dengan kondisi demikian maka seolah tidak ada keseimbangan materi yang menyangkut masalah kesehatan peserta didik. Hal ini mengakibatkan wawasan, pengetahuan siswa tentang kesehatan pada umumnya, dan kesehatan pribadi pada khususnya menjadi sangat minim. Dengan hal tersebut di atas maka kebiasaan sehari-hari mereka yang kurang baik bagi kesehatan tidak akan mengalami perbaikan menuju perilaku hidup sehat.

Komponen kesehatan terdiri dari beberapa bagian antara lain sebagai berikut.

a. Cardiovascular endurance (daya tahan cardiovascular) adalah berhubungan dengan peredaran darah dan pernafasan. Jadi yang dimaksud dengan daya tahan cardiovascular adalah keadaan atau kondisi tubuh yang mampu bekerja untuk waktu yang lama tanpa mengalami kelelahan yang berarti atau berlebihan setelah menyelesaikan pekerjaan tersebut.

b. Muscular endurance and strength (daya tahan otot dan kekuatan otot) adalah komponen yang sangat penting guna meningkatkan kondisi fisik secara keseluruhan, karena kekuatan otot merupakan daya penggerak setiap aktivitas fisik dan melindungi cedera.

c. Body composition (kesimbangan pertumbuhan tubuh). Maksudnya adalah kemampuan untuk mempertahankan neuromuscular kita dalam keadaan statis, keseimbangan ini berhubungan dengan kondisi dari beberapa ketrampilan serta kelincahan.

d. Flexibility (kelentukan). Kalau bicara mengenai kelentukan atau fleksibilitas biasanya mengacu pada ruang gerak sendi. (M.Ichsan,1989: 15) 
Komponen keterampilan terdiri dari lima bagian, antara lain sebagai berikut.

a. Muscular power (daya ledak otot) adalah kemampuan otot untuk melakukan gerakan dengan kuat dan cepat.

b. Agility (kelincahan) adalah orang yang mempunyai kemampuan untik mengubah arah dan posisi tubuh dengan cepat dan tepat pada waktu sedang bergerak, tanpa kehilangan kesimbangan dan kesadaran akan posisi tubuhnya. Bentuk-bentuk latihan untuk kelincahan antara lain : lari bolakbalik (shuttle run), lari zig-zag (zig-zag run) dan lari rintangan (obstacle run).

c. Speed (kecepatan) adalah kemampuan untuk melakukan gerakan-gerakan yang sejenis secara berturut-turut dalam waktu yang sesingkat-singkatnya atau kemampuan untuk menempuh suatu jarak tertentu dalam waktu yang sesingkat-singkatnya. Bentuk-bentuk untuk latihan kecepatan antara lain: interval training, lari akselerasi dan deselerasi.

d. Muscle bulk (ketebalan otot) adalah otot yang mempunyai ketebalan kuat akan mampu menimbulkan gerakan yang lebih cepat dan nantinya menghasilkan ketepatan gerak.

e. Posture (bentuk tubuh) adalah keadaan tubuh yang meliputi tinggi badan, berat badan, kelengkapan anggota badan dan berbagai ukuran bagian badan, bentuk badan pendek, berotot, ramping dan atletis. (M.Ichsan, 1989: 18)

Kesehatan pribadi siswa perlu mendapat perhatian dari pihak-pihak yang berkompeten. Definisi sehat menurut WHO adalah suatu keadaan sehat paripurna dan lengkap, mencakup kesehatan fisik, mental dan sosial dan bukan hanya keadaan yang bebas dari penyakit, cacat dan kelemahan. (Lutan dkk, 2000: 11 ).

Kesehatan pribadi dibagi dalam ruang lingkup kesehatan yang mempelajari mengenai beberapa hal, yaitu; (1) bekerja (gerak badan, tidur, 
istirahat, dan bersantai (rekreasi); (2) penampilan pribadi; (3) keadaan kesehatan perorangan; (4) pemeliharaan kesehatan panca indera; (5) pemeliharaan gigi; (6) penyakit tidak menular, peyakit ringan, dan bentuk tubuh; (7) fungsi alat-alat tubuh; dan (8) pertumbuhan. Sedangkan tujuan mempelajari kesehatan pribadi agar pribadi masing-masing (1) dapat memelihara kesehatan diri sendiri; (2) sopan santun dalam tindakannya; (3) dapat menularkan kepada keluarganya, masyarakat; (4) memperbaiki dan mempertinggi nilai-nilai kesehatan; dan (5) mendapat ketenangan dan ketenteraman jiwa yang ada dalam diri sendiri dan lingkungan sekitar. (Soetatmo, 1985: 1-2).

Dalam menjalani hidup sehari-hari kita sebaiknya selalu mengedepankan kesehatan tubuh dan jiwa kita karena sehat itu nikmat dan juga ada pepatah yang mengatakan bahwa seseorang tidak akan menghargai kesehatannya sendiri di saat ia masih sehat. Begitu pentingnya kesehatan sehingga ada orang yang rela membayar milyaran rupiah untuk kesehatan dirinya di saat dia sakit.

Metode itu sendiri adalah jalan yang dilalui atau yang ditempuh untuk mencapai suatu tujuan. Tujuan dari penelitian ini adalah untuk mengungkapkan, menggambarkan, dan menyimpulkan hasil pemecahan masalah melalui cara-cara tertentu sesuai dengan prosedur penelitian. Oleh karena itu metode penelitian yang digunakan penulis adalah metode deskriptif.

\section{HASIL PENELITIAN DAN PEMBAHASAN}

\section{Hasil Uji Coba Angket}

Berdasarkan hasil uji coba angket peranan mata pelajaran pendidikan jasmani maka diketahui terdapat butir soal yang tidak valid yaitu nomor angket 5 dan 12 . Maka butir angket tersebut kemudian diganti oleh penulis. Sedangkan hasil uji coba angket meningkatkan kesadaran kesehatan siswa 
maka diketahui terdapat butir soal yang tidak valid yaitu nomor angket 4 dan 11. Maka butir angket tersebut kemudian diganti oleh penulis.

Dari hasil uji reliabilitas butir angket maka diketahui seluruh butir angket dapat digunakan dengan hasil penghitungan reliablitas seluruh butir angket dengan metode ganjil genap sebesar 0.854 lebih besar dari pada t tabel $\mathrm{n}=10-2=8$ yaitu 2,306 .

\section{Hasil Perhitungan Nilai Rata-rata dan Simpangan Baku}

Hasil perhitungan nilai rata-rata dan simpangan baku dari setiap variabel maka diketahui besar rata-rata hasil angket variabel peranan mata pelajaran pendidikan jasmani sebesar 64.92 sedangkan besar simpangan baku 2.37 serta besar rata-rata hasil angket variabel kesadaran meningkatkan kesadaran kesehatan siswa sebesar 64.81 sedangkan besar simpangan baku variabel tersebut adalah 2.53 dapat dilihat pada tabel berikut.

Tabel 1. Data Penghitungan Nilai Rata-Rata Tiap Variabel

\begin{tabular}{ccc}
\hline Variable & Rata-rata & Simpangan Baku \\
\hline Mapel Pendidikan Jasmani & 64.92 & 2.37 \\
Kesadaran Kesahatan Siswa & 64.81 & 2.53 \\
\hline
\end{tabular}

\section{Hasil Penghitungan Uji Normalitas Data}

Berdasarkan hasil penghitungan uji normalitas data maka diketahui hasil uji normalitas ( $\mathrm{L}$ hitung) butir angket peranan mata pelajaran pendidikan jasmani sebesar 0.127 dan butir angket meningkatkan kesadaran kesehatan siswa sebesar 0.139 lebih kecil dari $\mathrm{L}$ tabel (30: 0,05) sebesar 0.161 maka seluruh butir angket dinyatakan normal.

Tabel 2. Hasil Penghitungan Uji Normalitas Tiap Variabel

\begin{tabular}{cccc}
\hline Variabel & L hitung & L tabel & Keterangan \\
\hline Mapel Pendidikan Jasmani & 0.127 & 0.161 & Normal \\
Kesadaran Kesehatan Siswa & 0.139 & 0,161 & Normal \\
\hline
\end{tabular}




\section{Korelasi Variabel Bebas (X) terhadap Variabel Terikat (Y)}

Korelasi (r) antara variabel bebas peranan «variabel1» $\left(\mathrm{X}_{1}\right)$ dalam «variabel2» $(\mathrm{Y})$ sebesar 0.748 dibandingkan dengan nilai $\mathrm{r}$ tabel dalam taraf nyata 5\% dan derajat kebebasan $(n-2) 37-2=35$, diketahui $r$ tabel sebesar 0.361 . Nilai $r$ hitung $>r$ tabel $(0.748>0.361)$ maka terdapat korelasi antara «variabel1» dengan «variabel2».

Tabel 3. Data Penghitungan Korelasi Dua Variabel

\begin{tabular}{ccc}
\hline $\mathrm{r}$ hitung & $\mathrm{r}$ tabel & Keterangan \\
\hline 0.748 & 0.361 & Terdapat Korelasi \\
\hline
\end{tabular}

\section{Uji signifikansi Variabel Bebas (X) terhadap Variabel Terikat (Y)}

Untuk menentukan signifikansi peranan mata pelajaran pendidikan jasmani dalam meningkatkan kesadaran kesehatan siswa, maka penulis menempuh langkah-langkah sebagi berikut.

a. Mencari nilai $t_{\text {hitung. }}$.

b. Menentukan kriteria penerimaan/penolakan hipotesis sebagai berikut.

Terima hipotesis nol $\left(\mathrm{H}_{0}\right)$ jika $\mathrm{t}_{\text {hitung }}$ lebih kecil dari $\mathrm{t}_{\text {tabel. }}$.

Tolak hipotesis nol $\left(\mathrm{H}_{0}\right)$ jika $\mathrm{t}_{\text {hitung }}$ lebih besar dari $\mathrm{t}_{\text {tabel. }}$.

c. Menghitung derajat kebebasan (dk).

$$
\begin{aligned}
\mathrm{dk} & =\mathrm{n}-2 \\
& =37-2 \\
& =35
\end{aligned}
$$

d. Menentukan taraf nyata. Taraf nyata yang diambil adalah 0,05

e. Menentukan $\mathrm{t}$ table. Pada daftar tabel distribusi $\mathrm{t}$ dengan $\mathrm{dk}=35$ karena nilai $\mathrm{t}$ untuk $\mathrm{dk}=35$ tidak ada maka penulis menggunakan nilai $\mathrm{t}$ dengan $\mathrm{dk}=30$ taraf nyata 0.05 yaitu sebesar 2.042 .

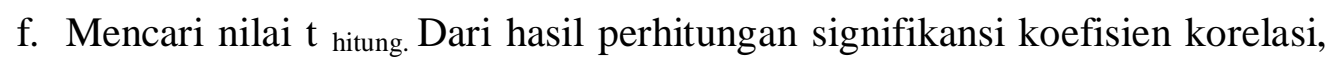
dapat diketahui nilai $t_{\text {hitung }}$ dari peranan mata pelajaran pendidikan jasmani dalam meningkatkan kesadaran kesehatan siswa yaitu sebesar 6.67. 
Kriteria penerimaan adalah tolak $\mathrm{H}_{0}$ apabila $\mathrm{t}$ hitung lebih besar dari $\mathrm{t}$ tabel, dan terima $\mathrm{H}_{0}$ apabila $\mathrm{t}$ hitung lebih kecil dari $\mathrm{t}$ tabel. Maka $\mathrm{t}$ hitung yang diperoleh signifikan pada taraf nyata 0.05 sehingga $\mathrm{H}_{0}$ ditolak $\left(\mathrm{t}_{\text {hitung }}>\mathrm{t}_{\text {tabel }}=\right.$ $6.67>2.042$ ), yang berarti bahwa terdapat hubungan yang signifikan antara peranan mata pelajaran pendidikan jasmani dengan meningkatkan kesadaran kesehatan siswa

Tabel 4. Hasil Uji Signifikansi Dua Variabel

\begin{tabular}{ccc}
\hline t hitung & $\mathrm{t}$ tabel & Keterangan \\
\hline 6.67 & 2.042 & Signifikan \\
\hline
\end{tabular}

\section{Indeks Determinasi antara Variabel Bebas terhadap Variabel Terikat}

Besarnya peranan mata pelajaran pendidikan jasmani sebagai variabel bebas dalam meningkatkan kesadaran kesehatan siswa sebagai variabel terikat, diperoleh hasil 55.96\%.

\section{SIMPULAN}

Berdasarkan hasil pengolahan dan analisis data mengenai peranan mata pelajaran pendidikan jasmani dalam meningkatkan kesadaran kesehatan siswa, yang dilakukan di Sekolah Dasar Negeri Tegalkalong III, dapat ditarik kesimpulan bahwa pelajaran pendidikan jasmani memiliki peranan yang sangat besar dalam meningkatkan kesadaran kesehatan siswa di lingkungan Sekolah Dasar Negeri Tegalkalong III. Besarnya peranan mata pelajaran pendidikan jasmani dalam meningkatkan kesadaran kesehatan siswa yaitu sebesar 55.96\%.

\section{DAFTAR PUSTAKA}

Giriwijoyo. 2007. Ilmu Faal Olahraga. Bandung: Fakultas Pendidikan Olahraga dan Kesehatan UPI.

Ichsan. 1989. Komponen Kesegaran Jasmani. Bandung: Rosda Karya. 
Kusnandar. 2000. Proses Pendidikan Jasmani. Bandung: Fakultas Olahraga UPI.

Lutan. 2000. Pentingnya Menjaga Kesehatan. Bandung: Fakultas Olahraga UPI.

Partakusumah. 1997. Dasar Pendidikan Jasmani. Bandung: Sinar Baru.

Sadoso. 1989. Makna dan Manfaat Kesegaran Jasmani. Jakarta: PN Balai Pustaka.

Soetatmo. 1985. Nilai-Nilai Kesehatan. Bandung: Fakultas Pendidikan Olahraga dan Kesehatan UPI.

Surakhmad. 1990. Pengantar Penelitian Ilmiah Dasar, Teknik, Metode. Bandung: Tarsito.

Sutrisno. 2001. Tujuan Pendidikan Jasmani. Semarang: Jembar.

Taryana. 2000. Prinsip Pendidikan Jasmani. Jakarta: Gramedia.

Zaenal. 2008. Aktivitas Pendidikan Jasmani. Surabaya: Usaha Nasional.

Syarifudin. 1997. Ruang Lingkup Pendidikan Jasmani. Jakarta: Rajawali. 